\section{Ungoutedly time for a change}

Dalbeth et $a l^{1}$ report the findings of dual-energy CT (DECT) scanning in patients with asymptomatic hyperuricaemia and symptomatic gout. This report reinforces the need to change our terminology, classification and management guidelines for gout as Dalbeth et $a l^{2}$ have already suggested in another study.

All current guidelines for the management of gout (recent review ${ }^{3}$ ) advise starting urate-lowering therapies for patients with tophi (urate deposits). Dalbeth et al have shown that urate deposits can be demonstrated by DECT scanning in patients with hyperuricaemia who have never experienced an acute episode of joint inflammation. Additionally, Dalbeth et al (and Choi et al ${ }^{4}$ ) have demonstrated that DECT scans show that urate deposits are sometimes present in patients with a history of acute joint synovitis but no bedside evidence of tophi. Tophi are urate deposits whether we can see them clinically or need a DECT scan. Does this mean that all patients with urate deposits on DECT scanning need urate-lowering therapy as the current guidelines suggest or are the guidelines not applicable in this setting?

DECT scanning has recently been suggested to be useful as 'the second line diagnostic evaluation of patients with suspected gouty arthritis' ${ }^{5}$ DECT scanning is a very useful tool for demonstrating urate deposits but will have lesser value in assessment of an acute episode of joint inflammation. Dalbeth et al have again shown that the value of DECT scanning is dependent on the 'stage' of the disease at which the patient is in the disease process. Even the sensitivity and specificity of DECT scanning study ${ }^{4}$ used a patient group with confirmed crystal positive disease and thus may not be applicable across all stages of the gout spectrum.
The time is overdue for new definitions of the 'stages' of gout, so that there is effective communication of information from the increasing number of research studies.

\section{Graham Reid}

Correspondence to Dr Graham Reid, University of British Columbia, 306-888 West 8th Avenue, Vancouver, British Columbia, V5Z 3Y1, Canada; reidgd@gmail.com

Competing interests None.

Provenance and peer review Not commissioned; internally peer reviewed.

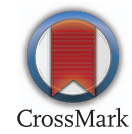

To cite Reid G. Ann Rheum Dis 2015;74:e50.

Received 2 March 2015

Accepted 4 March 2015

Published Online First 31 March 2015

Ann Rheum Dis 2015;74:e50. doi:10.1136/annrheumdis-2015-207534

\section{REFERENCES}

1 Dalbeth $\mathrm{N}$, House ME, Aati $\mathrm{O}$, et al. Urate crystal deposition in asymptomatic hyperuricemia and symptomatic gout: a dual energy CT study. Ann Rheum Dis 2015. Published Online First: 30 Jan 2015. doi:10.1136/annrheumdis-2014-206397

2 Dalbeth N, Fransen J, Jansen TL, et al. New Classification criteria for gout: a framework for progress. Rheumatology 2013;52:1748-53.

3 Khanna PP, FitzGerald J. Evolution of management of gout: a comparison of guidelines. Curr Opin Rheumatol 2015;27:139-46.

4 Choi HK, Al-arfaj AM, Eftekhari A, et al. Dual energy computed tomography in tophaceous gout. Ann Rheum Dis 2009;68:1609-12.

5 Bongartz T, Glazebrook KN, Kavros SJ, et al. Dual-energy CT scan for the diagnosis of gout: an accuracy and diagnostic yield study. Ann Rheum Dis 2014. Published Online First: 25 Mar 2014. doi:10.1136/annrheumdis-2013-205095 